\title{
Genetic evaluation of the self-sustaining status of a population of the endangered Danube salmon, Hucho hucho
}

\author{
S. Weiss • T. Schenekar
}

Received: 6 October 2015/Revised: 1 March 2016/Accepted: 2 March 2016/Published online: 12 March 2016

(C) The Author(s) 2016. This article is published with open access at Springerlink.com

\begin{abstract}
A new multiplex microsatellite protocol was developed for population screening of the endangered Danube salmon (or huchen) Hucho hucho. Allelic variation was screened at five newly cloned and four previously published loci in 246 samples to help evaluate the self-sustaining status of an urban population of huchen in the framework of a controversial environmental assessment in the Mur River, Austria. The loci revealed 78 alleles (mean $=8.6$ ), and in the Mur River an average expected heterozygosity of 0.668 . We inferred that the huchen population in and around the city of Graz is self-sustaining based on the following evidence, which includes both genetic and non-genetic sources of information: (1) there is little to no current stocking; (2) presence of juvenile huchen in multiple year classes; (3) sighting of spawning events; (4) documentation of 14 spawning redds; (5) no deviation from Hardy-Weinberg equilibrium; and (6) limited number of recaptures or parental matches with presumed parent fish of stocking operations. We discuss the potential application of such an analysis in evaluating threatened huchen populations throughout their native distribution.
\end{abstract}

Handling editor: M. Power

S. Weiss $(\varangle) \cdot$ T. Schenekar

Institute of Zoology, University of Graz, Universitätsplatz

2, 8010 Graz, Austria

e-mail: steven.weiss@uni-graz.at
Keywords Huchen - Microsatellites - Stocking · Parentage analysis $\cdot$ IUCN $\cdot$ European habitat directive

\section{Introduction}

The endangered Danube salmon Hucho hucho (Linnaeus, 1758), or huchen as commonly known in Central Europe, is among the largest salmonid fishes in the world. Endemic to the Danube basin, huchen have lost, according to Holčík (1990), two-thirds of its global distribution and up to $90 \%$ of its original habitat in particular regions, such as Austria (Schmutz et al., 2002). The species is endangered following IUCN criteria (Freyhof \& Kottelat, 2008) and listed under Annexes II and V of the European Habitat Directive, as well as Appendix III of the Bern Convention. These listings oblige EU member states to certain responsibilities concerning the protection and rehabilitation of huchen within their natural range. While a number of factors such as overfishing and various forms of river channel engineering have been responsible for historical losses of the species, ongoing hydropower expansion is the most extensive current threat to remaining populations (Ihut et al., 2014; Freyhof et al., 2015). Several genetic studies have addressed the phylogenetic position and phylogeographic structure of the species throughout its native range (Weiss et al., 2011; Marić et al., 2014a), but population studies have been limited to those of Geist et al. (2009) and Marić 
et al. (2014b). While a few microsatellite markers were applied in these studies, there has yet to be an efficient multiplex protocol published to support population genetic typing in a conservation context, and no study has thus far attempted to evaluate the self-sustaining status of a population that received stocked hatchery material. Like many other salmonid fishes, some populations of huchen are managed, and especially in Central Europe, hatchery-reared individuals are routinely stocked into flowing waters with the goal of enhancing or rehabilitating natural stocks. Annex II of the European Habitat Directive (1992) clearly states that only "natural populations" of huchen warrant protection at the state level under this directive. This clause is similar or identical in meaning to the definition (or limitation) that only "wild populations" are considered for red list nomination by the IUCN red list criteria (IUCN 2012). Both documents explicitly state that individuals released from captivity are not considered, but neither document implies or states that the existence of released individuals in any way degrades the conservation status of a population. Clearly, the concept of a wild or natural population is limited to the understanding that the population can sustain itself, and is within the natural range of its distribution. Thus, where species are managed by supplemental stocking, the issue of whether or not this population is "natural" or "wild" under the definition of existing legislation will become increasingly relevant as the exploitation of rivers for various economic interests continues to increase. Evaluating self-sustainability can involve a number of approaches including the identification of viable spawning areas, documentation of an age-structured population including young-of-the-year individuals, and enumeration of the relative contribution of stocked versus wild recruitment. This latter issue is complex, as documentation of surviving hatchery individuals, or even an accurate estimate of the relative contribution of hatchery individuals does not necessarily clarify what the population would look like if no stocking were taking place. In this study, we aim to evaluate the selfsustaining status of a huchen population in and around an urban area using population genetic analyses together with field observations and sampling data.

To support this goal, we cloned new highly polymorphic microsatellite loci and developed an efficient multiplex protocol for typing huchen, and evaluated the effectiveness of this protocol in the framework of a controversial hydropower development project in the Mur River, in Graz Austria. The Mur River harbors the largest self-sustaining population of huchen in Austria, primarily in its upper reaches, but fragmented populations or sub-populations also exist at least as far downstream as Graz, the second largest city in the country. Local energy authorities claim that no huchen reproduction takes place in Graz, and thus, no self-sustaining population exists in and around the city.

\section{Methods}

Genetic markers

We cloned new tetranucleotide microsatellite loci using a selective hybridization approach (Karagyozov et al., 1993) and streptavidin-coated magnetic beads (Kandpal et al., 1994; Kijas et al., 1994; Paetkau, 1999). This approach was improved by Diniz et al. (2007) and McPherson et al. (2001), and finally our protocol followed the double-hybridization method as outlined in Winkler \& Weiss (2008), including all details of adaptor and probe design.

Approximately 1600 positive clones were screened, $20 \%$ of which had the appropriate size and were thus sequenced on an ABI 3130xl Genetic Analyzer (Life Technologies). From these, 58 sequences revealed enough flanking space for primer design. Of 58 loci tested, only five loci revealed clear and polymorphic (across multiple individuals) electropherograms and no evidence of duplication. To expand the number of loci, we tested an additional 19 published primer pairs from huchen or other salmonids and subsequently added four of these loci to our protocol: HLJZ023 (Tong et al., 2006), OMM1064 (Froufe et al., 2005), TAR101 (Diggs \& Ardren, 2008), and ONE2 (Scribner et al., 1996). Table 1 summarizes the loci motifs, annealing temperatures, and allelic ranges of all loci used in this study. Six loci (GATA501, GACA448, GACA142, GACA559, HLZ023 \& OMM1064) were combined into one multiplex reaction, TAR101 \& ONE2 into a duplex reaction, and the remaining locus, because a differing annealing temperature was amplified singularly; all reactions were carried out with the Type-It Microsatellite PCR Kit (Qiagen) following the manufacturer's instructions. The dye-labeled PCR products $(1 \mu \mathrm{l})$ were dried at $60^{\circ} \mathrm{C}$ for $30 \mathrm{~min}$ and 


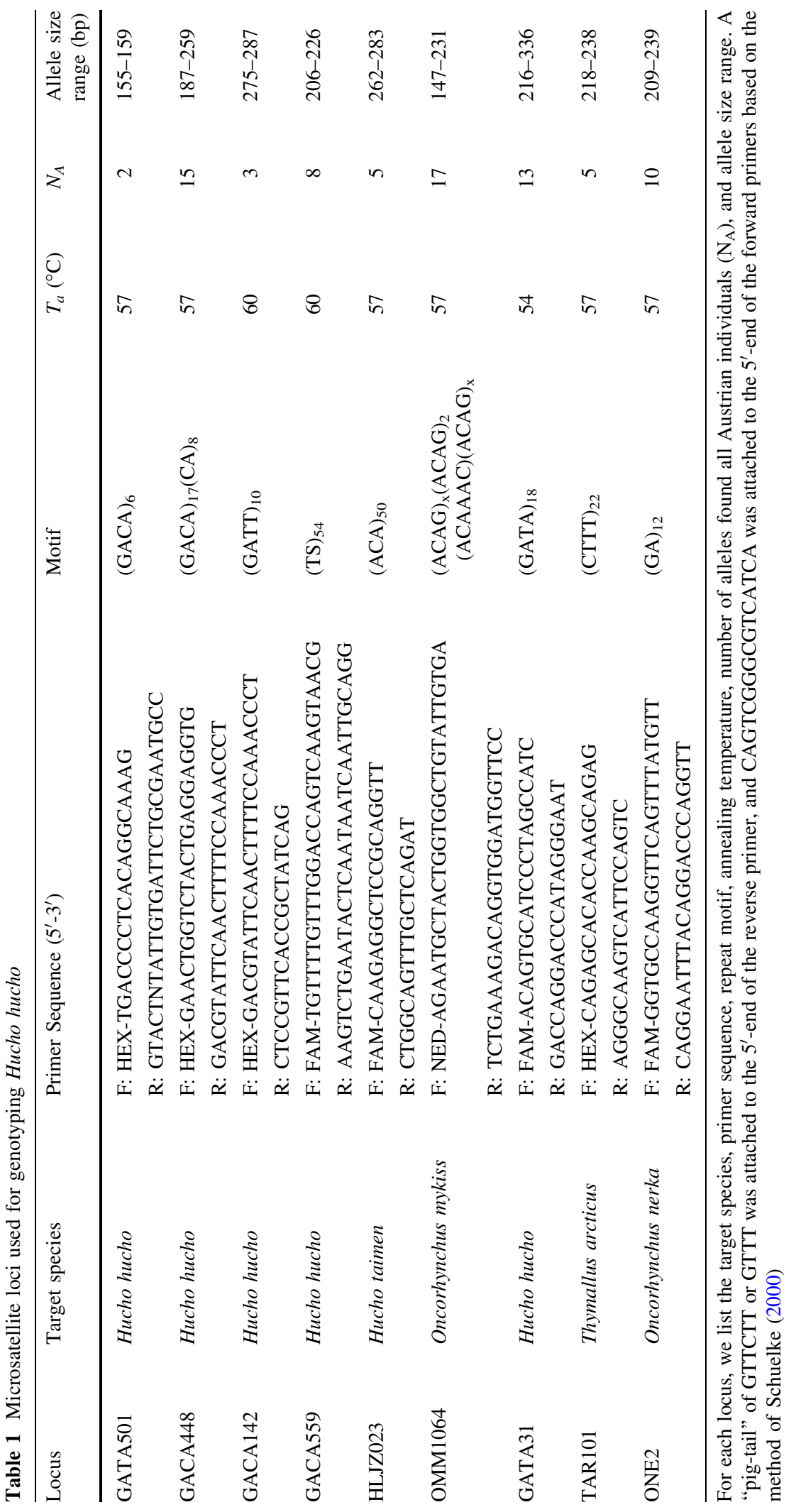


resuspended in $10 \mu \mathrm{l} \mathrm{Hi}^{-\mathrm{Di}^{\mathrm{TM}}}$ Formamide with $0.25 \mu$ GeneScan $^{\mathrm{TM}} 500 \mathrm{ROX}^{\mathrm{TM}}$ Size Standard (Life Technologies), incubated at $95^{\circ} \mathrm{C}$ for $5 \mathrm{~min}$, and cooled on ice for at least 5 min. Products were subsequently loaded onto a 3130xl Genetic Analyzer (Life Technologies) and analyzed with GeneMapper Software (version 3.7, Life Technologies).

\section{Sampling}

Tissue samples (ca. $1 \mathrm{~mm}^{2}$ fin clips) of free-living huchen were obtained opportunistically from (1) fishing organizations or fisherman (for nearly all adult fish); (2) electric-fishing sampling efforts carried out by private parties contracted by the provincial government; or (3) during the draining of side canals, or in one case (Lassnitz) the re-routing of entire river channel to make room for a new railroad line, where despite rescue efforts a large number of juvenile huchen were unintentionally killed. Additional samples stem from 19 brood fish from a small private hatchery in Lower Austria, from which the local fishery organization would purchase fish for stocking. The brood fish originally stem from the upper Mur River $(N=14)$, the Pielach River $(N=4)$, and one individual of unknown origin. Leading up to this study, the last recorded stocking event in the Graz vicinity was carried out in 2008 with 10 , ca. 40-cmlong fish (3-4 years old), all of which were genetically sampled before their release north of the city. For general comparative purposes, but also to evaluate if our protocol could be applied outside the study region, we included samples from throughout the natural range of the huchen. In total, 246 samples from 25 locations were analyzed (Fig. 1; Table 2).

\section{Analysis}

Observed and expected heterozygosity, the mean number of alleles and allelic ranges were calculated in Arlequin v 3.11 (Excoffier et al., 2005). Deviations from Hardy-Weinberg equilibrium (HWE; using the intrapopulation fixation index $F_{\text {IS }}$ ) were calculated using FSTAT v2.9.3.2 (Goudet, 2002). For evaluation of HWE, only the Mur river samples were used, whereby samples were pooled into one of four groups (Graz City, Graz vicinity North, South of Graz and Upper Mur). Graz City was defined by the city limits, which corresponds to an approximately $10 \mathrm{~km}$-long reach of the Mur River. Graz vicinity North, stretched from the northern city limits approximately located at the Weinzödl weir, ca. 15 river km north to the town of Peggau, South of Graz extends from the southern city limits downstream approximately 50 river $\mathrm{km}$ to the town of Radkersburg on the Slovenian border. For the purposes of this report, the Upper Mur is defined as the reach between Murau and St. Michael.

Genetic relationships among individuals were displayed following a Factorial Correspondence Analysis (FCA) with the GENETIX software package (Belkhir et al., 2004). Differences among samples are based on the presence and absence of alleles and are displayed in two dimensional space, using pairs of FCA vectors.

We tested for potential parent-offspring relationships between the 19 hatchery brood fish of known sex (assumed as potential parents) and the sampled fish (assumed as offspring) caught in the Mur River in and around $\operatorname{Graz}(N=96)$, including the 10 stocked fish using Cervus ver. 3.0.3 (Kalinowski et al., 2007). We incorporated both an exclusion principle and likelihood scores (LOD) based on estimated allele frequencies. Following guidelines found in Jones et al., (2010), we allowed for up to two allelic mismatches in a triad (mother-father-offspring) and a $1 \%$ genotyping error rate to account for both typing error and mutation. Putative triads were accepted if they had $<3$ mismatches and a positive LOD, meaning simply that the likelihood of the putative parents exceeds the likelihood that they are not the true parents.

\section{Results}

Among the 246 multi-locus genotypes produced, six genotypes, all within Graz and its vicinity were duplicates and thus removed from subsequent analysis. Duplicate genotypes herein are assumed to stem from the same fish and thus document a recapture event, based on the improbability of duplicate multilocus genotypes naturally occurring in the population. Using the simple product rule for calculating the probability of a multi-locus genotype, assuming nonlinked loci, Hardy-Weinberg equilibrium, and an accurate estimate of allele frequencies in the pooled population (Graz City, Graz vicinity North, South of Graz), the probability of finding these duplicate multilocus genotypes in unrelated individuals ranged from 1 in $10^{-9}$ to 1 in $10^{-12}$. While the probability of 


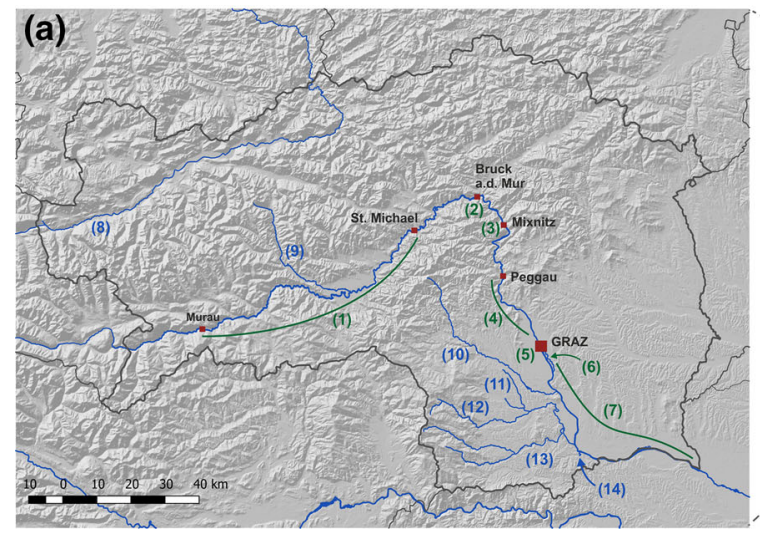

Fig. 1 a Location of the sampled stretches of the Mur River (1-7), as well as the additional sampled rivers in the province of Styria (8-14), and $\mathbf{b}$ location of the sampled rivers in Austria and the Balkan countries. The numbers correspond to the following rivers/river stretches: (1) Upper Mur, (2) Mur Bruck, (3) Mur

finding a duplicate multi-locus genotype in fullsiblings for this dataset would be at least four to five orders of magnitude lower, considering the small size of our dataset, we conclude that duplicates were indeed recaptures. This assumption is further supported by the fact that the recaptures made biological sense in terms of fish size and location.

A projection of the first two factors of the FCA shows that the majority of samples cluster close together, with only the distant samples (Tisa River in Romania, Lim River and Lake Plav in Montenegro, Vrbas River in Bosnia-Herzegovina, and the Drina River in Serbia) showing significant divergence from the bulk of the samples (Fig. 2). After removing nonAustrian samples and re-calculating these factors, one gains an overall picture of the general lack of genetic subdivision among Austrian huchen, relative to the divergence seen in distant drainages (Fig. 3).

General population level statistics are provided for the Mur River populations only (Table 3). Tests for HWE as well as estimates of heterozygosity are provided both for all nine loci and with the ONE2 removed. This latter locus showed significant deviations from HWE throughout the data set and a subsequent evaluation with the program MicroChecker ver. 2.2 (Van Oosterhout et al., 2004) strongly supported the presence of null alleles at this locus. For the focal area of this study, both samples within the city limits of Graz, as well as the region just north of Graz were in HWE. By pooling these samples

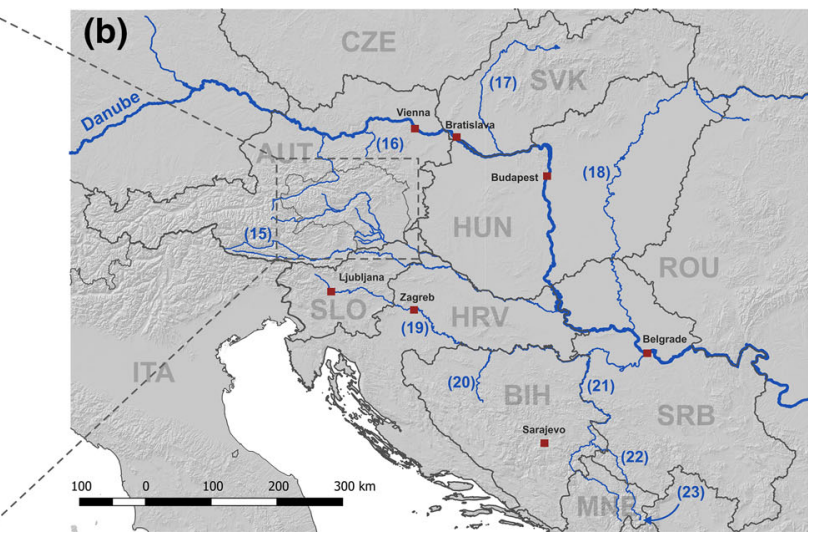

Mixnitz, (4) Mur Graz vicinity north, (5) Graz city, (6) Mur Fernitz Canal, (7) Mur South of Graz, (8) Enns, (9) Pöls, (10) Kainach, (11) Oisnitzbach, (12) Lassnitz, (13) Sulm, (14) Gamlitzbach, (15) Pielach, (16) Gail, (17) Vah, (18) Tisa, (19) Sava, (20) Vrbas, (21) Drina, (22) Lim, and (23) Lake Plav

into one population, there was a deviation from HWE only when including the aberrant ONE2 locus (Table 3). This supports that these river stretches could be considered as a single population, although currently there is no viable upstream fish pass facility at the weir at the north (upstream) end of the city of Graz, and there was a low but significant pairwise $F_{\mathrm{ST}^{-}}$ value $(0.024$, Table 4$)$ between these adjacent river reaches. Samples from the Upper Mur, the heart of the huchen's distribution in the river (Schmutz et al., 2011), were also in HWE and based on the FCA graph showed no significant deviation from samples in and around the city of Graz; however, there was a low but statistically significant $F_{\mathrm{ST}}$-value $(0.009$, Table 4$)$ between these two disjunct river reaches, separated by $50-100$ river kilometers and a number of impassable weirs. In contrast, samples from various reaches and tributaries of the Mur south of Graz showed a strong deviation from HWE indicating that more than one population was sampled, and/or particular subpopulations are predominated by artificial propagation. Nonetheless, the highest pairwise $F_{\mathrm{ST}}$-value among Mur River sub-populations (Graz vicinity north and South of Graz) was only 0.028 and thus the common origin and relatively close relationship of Mur River huchen, despite the fact that some likely introgression from non-Mur sources is underscored.

Ignoring the 10 stocked and genotyped fish in the data bank (only one of which was recaptured), only a single multi-locus genotype for a wild-caught 
Table 2 List of samples used in this study

\begin{tabular}{|c|c|c|c|c|c|c|}
\hline \multirow[t]{2}{*}{ River } & \multirow[t]{2}{*}{ Site } & \multicolumn{4}{|c|}{ Number of individuals } & \multirow{2}{*}{$\begin{array}{l}\text { Sample } \\
\text { locality }\end{array}$} \\
\hline & & Adults $(>60 \mathrm{~cm})$ & Juveniles & Unknown & Total & \\
\hline \multirow[t]{8}{*}{ Mur } & Upper Mur & 4 & 42 & & 46 & (1) \\
\hline & Bruck a.d. Mur & 1 & & & 1 & (2) \\
\hline & Mixnitz & 1 & & & 1 & (3) \\
\hline & Graz vicinity North & 28 & 13 & 1 & 42 & (4) \\
\hline & Graz City & 11 & 19 & 6 & 36 & (5) \\
\hline & Fernitz Canal & & 6 & 1 & 7 & (6) \\
\hline & South of Graz & 7 & 3 & & 10 & (7) \\
\hline & Mur subtotal & & & & 143 & \\
\hline \multirow[t]{12}{*}{ Other Austrian sites } & Enns & 1 & & & 1 & (8) \\
\hline & Pöls & & & 1 & 1 & (9) \\
\hline & Kainach & & 1 & 2 & 3 & (10) \\
\hline & Oisnitzbach & & 2 & & 2 & (11) \\
\hline & Lassnitz & & 19 & & 19 & (12) \\
\hline & Sulm & 2 & 14 & & 16 & (13) \\
\hline & Gamlitzbach & & & 1 & 1 & (14) \\
\hline & Pielach & 11 & 2 & & 13 & (15) \\
\hline & Gail & & & 1 & 1 & (16) \\
\hline & Brood fish* & 19 & & & 19 & \\
\hline & Stocked fish** & & 10 & & 10 & \\
\hline & Austrian subtotal & & & & 229 & \\
\hline \multirow[t]{8}{*}{ Non-Austrian sites } & Vah & & & 3 & 3 & (17) \\
\hline & Tisa & & & 3 & 3 & (18) \\
\hline & Sava & & & 2 & 2 & (19) \\
\hline & Vrbas & & & 1 & 1 & (20) \\
\hline & Drina & & & 3 & 3 & (21) \\
\hline & Lim & & & 3 & 3 & (22) \\
\hline & Lake Plav & & & 2 & 2 & (23) \\
\hline & Grand total & & & & 246 & \\
\hline
\end{tabular}

Shown is the river of origin, and for the Mur River this is shown as river sections as defined in the text. Sample locality corresponds to those shown in Fig. 1. Where possible, fish are labeled as adults $(>60 \mathrm{~cm})$ or juveniles $(<60 \mathrm{~cm})$. Site information for non-Austrian sites can be found in Weiss et al. (2011)

* Brood fish used in a hatchery operation in Lower Austria (see text)

** 3- to 4-year-old progeny from this same hatchery, stocked into the Mur north of Graz in 2008

individual, caught north of Graz, showed no locus mismatch with a pair of brood parental fish from the hatchery. This result differs from that reported in Weiss and Schenekar (2012), whereby the calculations therein did not consider the sex of the parent. Including one or two mismatches, and accepting only theoretical triads (mother-father-offspring) with a positive LOD score, nine additional potential hatchery offspring could be identified. Six triads revealed a single mismatch, two in Graz City, three in Graz vicinity North, and one south of Graz. Three additional triads revealed two allelic mismatches with their presumed parents, all adults $(67-115 \mathrm{~cm})$, with one from Graz City, one from Graz vicinity North, and one south of Graz. All individuals with $>2$ mismatches revealed negative LOD scores. The LOD likelihood score for the 10 accepted triad matches ranged from $2.82 \times 10^{13}$ to $6.85 \times 10^{14}$. Only four of the stocked fish could be assigned parents, demonstrating that 3-4 years prior to 2008 (the age of these fish at the 


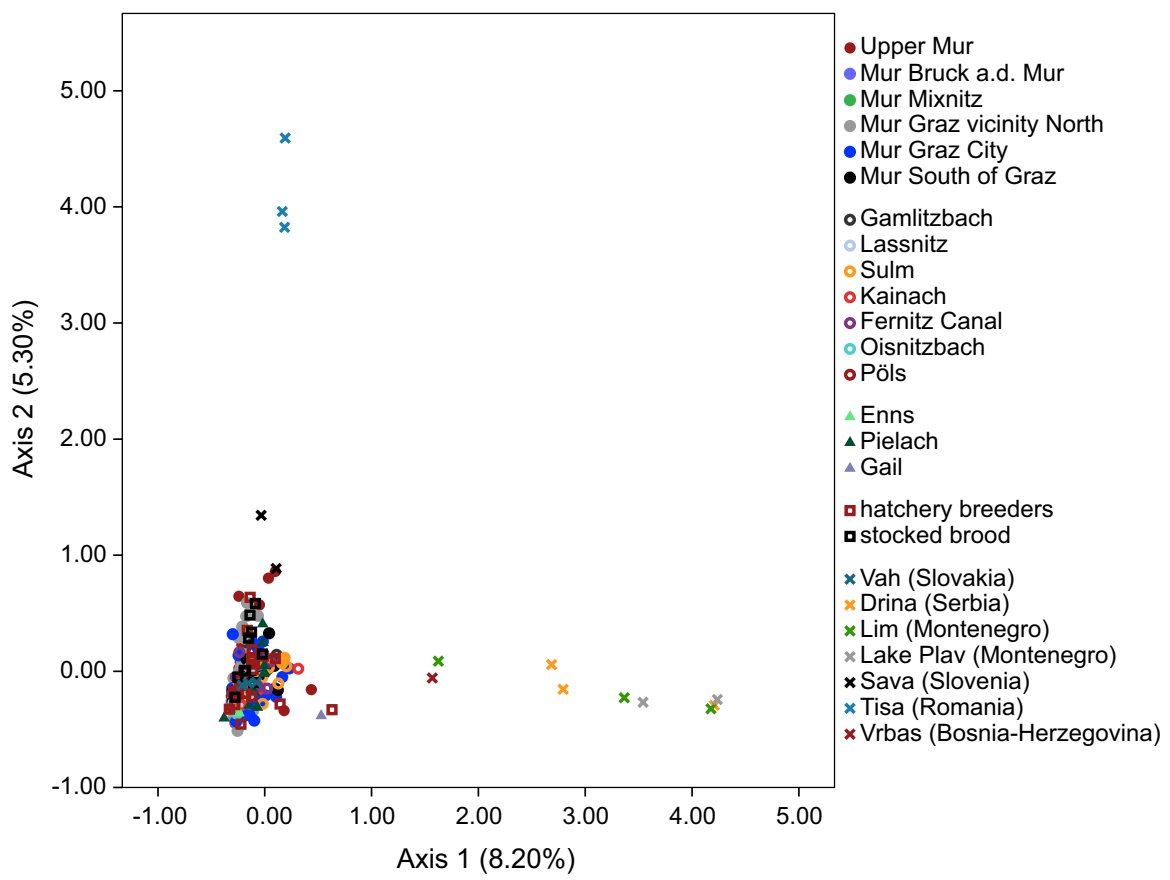

Fig. 2 Axes 1 and 2 of the Factorial Correspondence Analysis (FCA) of all huchen samples typed for 8 loci (ONE2 removed). Percentages on axes correspond to percentage of variability explained by the respective factor

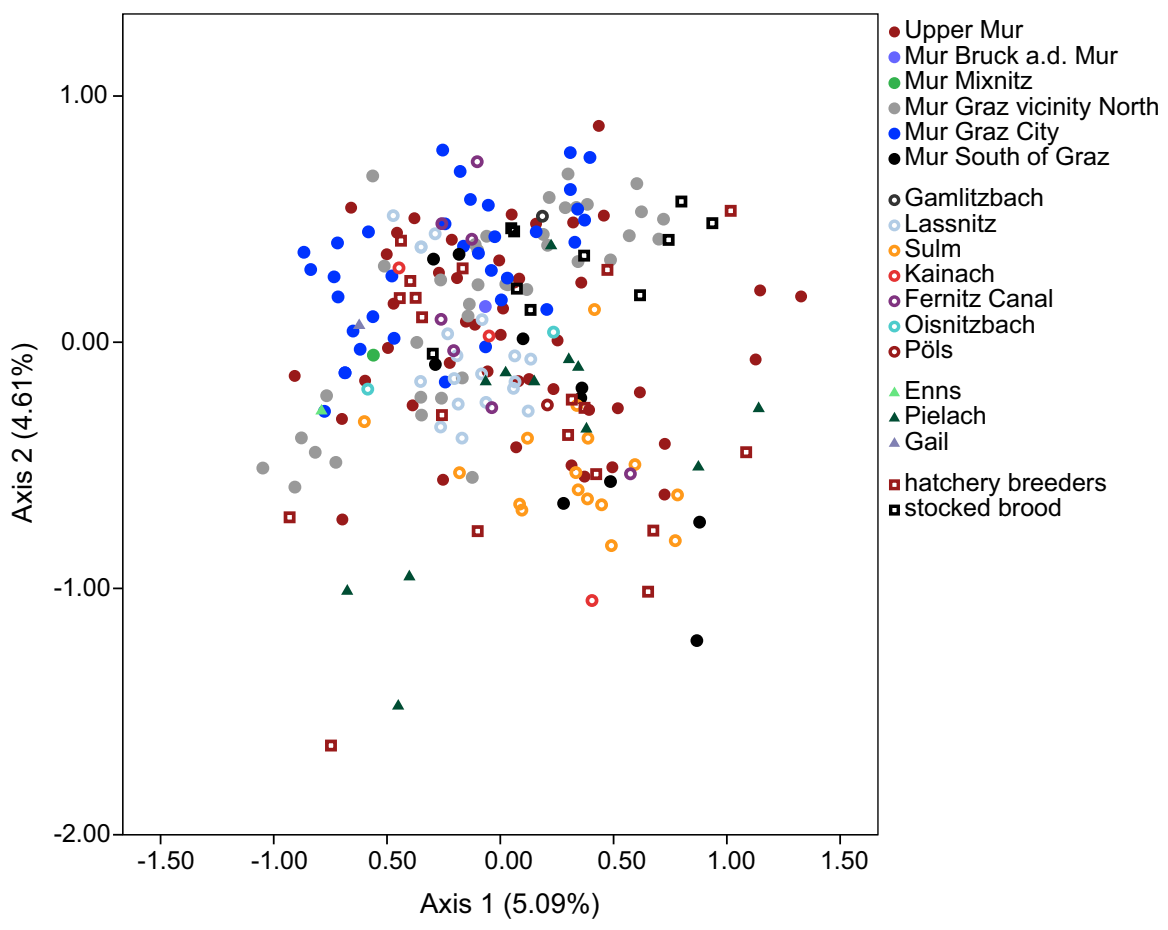

Fig. 3 Axes 1 and 2 of the Factorial Correspondence Analysis (FCA) of Austrian huchen samples typed for 8 loci (ONE2 removed). Percentages on axes correspond to percentage of variability explained by the respective factor 


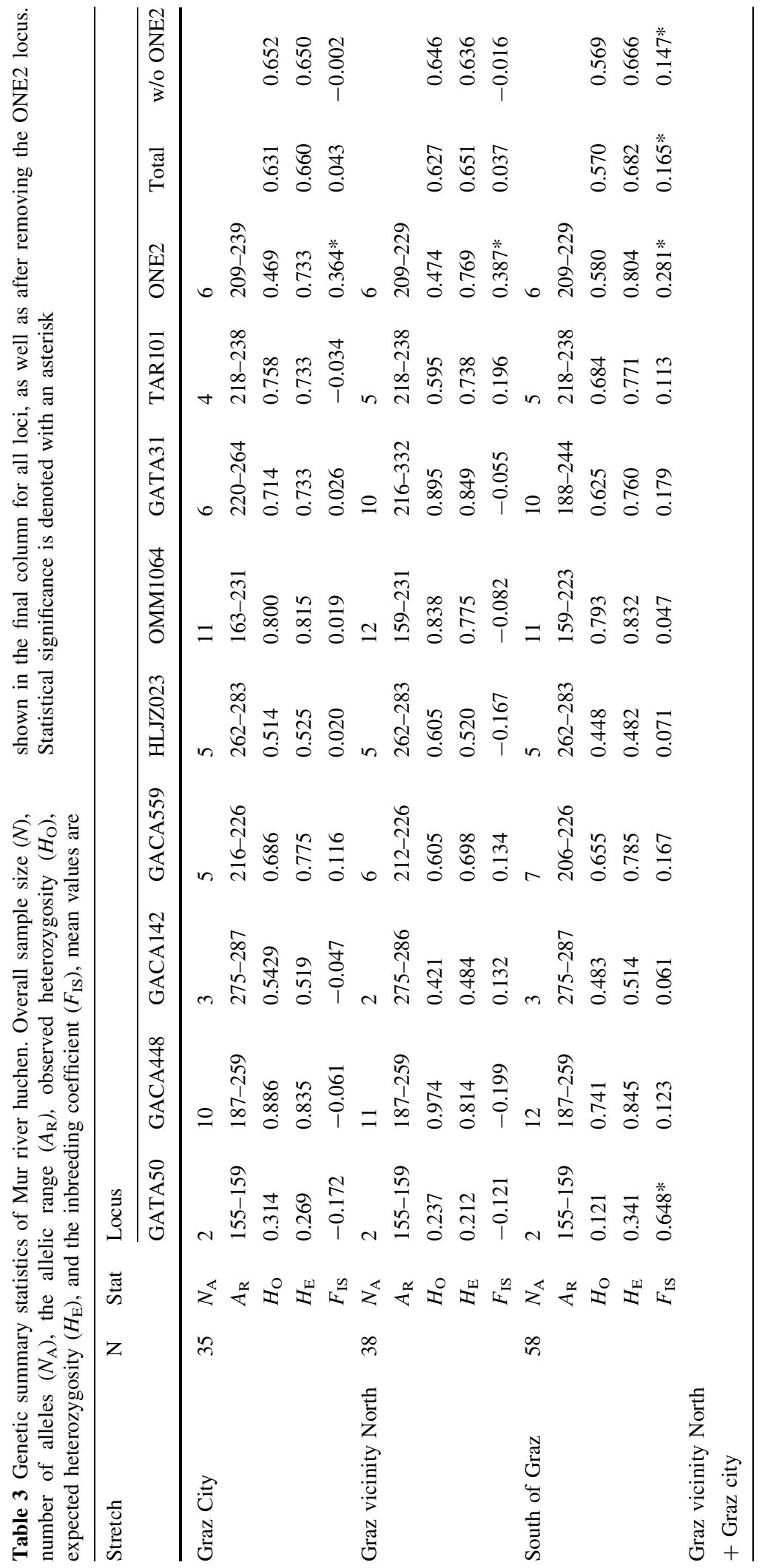


Table $4 F_{\mathrm{ST}^{-}}$-values between the defined groups of samples in the Mur River

\begin{tabular}{|c|c|c|c|c|c|}
\hline & Upper Mur & $\begin{array}{l}\text { Graz vicinity } \\
\text { North }\end{array}$ & Graz City & $\begin{array}{l}\text { Graz City \& } \\
\text { Graz vicinity North }\end{array}$ & South of Graz \\
\hline Upper Mur & - & & & & \\
\hline Graz vicinity North & 0.00659 & - & & & \\
\hline Graz City & $0.02326^{*}$ & $0.02396 *$ & - & & \\
\hline Graz City \& Graz vicinity North & $0.0088^{*}$ & -0.00125 & -0.00032 & - & \\
\hline South of Graz. & $0.01412 *$ & $0.0284 *$ & $0.02956 *$ & $0.02333 *$ & - \\
\hline
\end{tabular}

A significant $F_{\mathrm{ST}}$-value is indicated by an asterisk

time of stocking), at least one of the parental fish was not in our brood database. We note that for all offspring assignments, only three fathers and six mothers were involved, although 19 potential parents were sampled. A rough estimation of the proportional hatchery contribution to the population in and around Graz was ca. 15\% ( 7 of 46) for adults and 6\% (3 of 49) for juveniles. While the lack of all parental genotypes for the past may underestimate the contribution for all adults, it has little to no effect on the estimated contribution of the juveniles, as most were smaller than the minimum stocking size (Table 5) and/or stem from a time period where all parental genotypes are included in the analysis. The adult fish ranged from 60 to $115 \mathrm{~cm}$, thus reflecting, at least theoretically, survival of stocked individuals of the very recent past, as well as up to 10 years or more in the past. The limited stocking records demonstrate three important points for the evaluation of our results: (1) no stocking has taken place in the city limits since 1993; (2) 1997 was the last year huchen under $3+$ years in age were stocked in the entire region, meaning that most if not all sub-adults are naturally reproduced; and (3) a very limited number of fish of $3+$ years old have been stocked in the last decade, all north of the city (Table 5).

\section{Discussion}

Our multiplex microsatellite protocol is sufficient for evaluating population structure and tracing parentoffspring relationships (when parents and their sex are known) among hatchery and wild produced huchen individuals. We have used this protocol and our genetic results together with independent biological information to conclude that the greater proportion of the huchen population in and around Graz, at least in the most recent past, stems from natural reproduction, and thus, the population is self-sustaining (at least up until the time of this study) despite the occurrence of stocking. By self-sustaining, we do not imply that no gene flow from nearby river reaches occurs-but rather that the health of the population is not dependent on hatchery supplementation-a conclusion that is relevant for conservation purposes.

\section{Genetic evaluation of stocked versus wild fish}

For most huchen populations, it will not be possible to distinguish hatchery versus wild fish genetically without complete knowledge of the genetic composition of the parental brood stock. This is because there is a relatively limited amount of genetic diversity for the species (Weiss et al., 2010), and brood stocks generally stem from the same or nearby river systems, with little to no genetic divergence from the managed population. If a brood stock is foreign to a drainage, and has been used for the first time, then general population assignment tests might work, but in practice, this will rarely be the case with huchen. However, for most managed populations, if the brood parents are genotyped, it is possible through parentage analysis to robustly exclude individuals as offspring of hatchery parents, if they indeed stem from wild parents. This is what we did in our study, although complete knowledge of all potential parents for all possible offspring was not available. The power to assign parentage across different studies will depend on various factors, including whether or not all potential parents have been genotyped, if the sex of each potential parent is known, and the number and heterozygosity of the markers successfully typed. It should be emphasized that knowing the individual sex of potential parents greatly decreases the potential 
Table 5 Huchen stocking records from the local fishery organization "Arbeiterfischereiverein-Graz" for the Mur river between 1993 and 2011

\begin{tabular}{|c|c|c|c|c|}
\hline Year & Number & $\begin{array}{l}\text { Age- } \\
\text { class }\end{array}$ & $\begin{array}{l}\text { Approx. } \\
\text { size }(\mathrm{cm})\end{array}$ & Reach \\
\hline 1993 & 120 & $1+$ & 18 & Mur north \\
\hline \multirow[t]{2}{*}{1994} & 200 & $2+$ & 27 & Mur north \\
\hline & 2000 & $0+$ & 6 & Mur north \& south \\
\hline \multirow[t]{2}{*}{1995} & 100 & $2+$ & 27 & Mur north \\
\hline & 300 & $1+$ & 18 & Mur north \\
\hline \multirow[t]{3}{*}{1996} & 350 & $1+$ & 18 & Mur north \\
\hline & 200 & $2+$ & 27 & Mur north \\
\hline & 100 & $3+$ & 36 & Mur north \\
\hline \multirow[t]{3}{*}{1997} & 2300 & $0+$ & 7 & Mur north \& south \\
\hline & 200 & $2+$ & 27 & Mur north \\
\hline & 108 & $3+$ & 42 & Mur north \& south \\
\hline 1998 & 350 & $3+$ & 42 & Mur north \& south \\
\hline 1999 & 100 & $3+$ & 42 & Mur north \\
\hline 2000 & 0 & & & \\
\hline 2001 & 0 & & & \\
\hline 2002 & 0 & & & \\
\hline 2003 & 43 & $3+$ & 42 & Mur north \\
\hline 2004 & 42 & $3+$ & 42 & Mur north \\
\hline 2005 & 10 & $3+$ & 42 & Mur north \\
\hline 2006 & 35 & $3+$ & 42 & Mur north \\
\hline 2007 & 48 & $3+$ & 42 & Mur north \\
\hline 2008 & 25 & $3+$ & 42 & Mur north \\
\hline 2009 & 11 & $3+$ & 42 & Mur north \\
\hline $2010+$ & \multicolumn{4}{|c|}{ Stocking operations stopped } \\
\hline
\end{tabular}

Note that since 1993, no huchen were stocked within the city limits, and 1997 was the last year that $0+$ huchen were stocked in the region. Fish sizes are approximations. Mur North Weinzödl weir at the north end of the city upstream to Peggau; Mur South the district Großsulz downstream to Wildon

parental-offspring combinations, thus increasing the probability of confidently excluding wild-born individuals as hatchery offspring. After removal of one of our microsatellite loci (ONE2), we had eight moderately polymorphic loci with a mean expected heterozygosity of 0.689 (calculated from Graz region plus parental fish) or approximately 0.651 (Graz region alone). While these loci were adequate for our study, another river system, or another region, might exhibit lower heterozygosity, and thus an increase in the number of loci typed is recommended. The ability to detect recaptures, as well as to differentiate between a recapture and siblings, will also depend on the history (or more precisely the coancestry) and size of the population being investigated. Very large populations, for example, or a highly inbred population will exhibit a higher probability of identical genotypes appearing in different individuals compared to smaller and/or more outbred populations-for an enlightening discussion on the issue see Weir (2007).

Despite the usefulness of the genetic data, we emphasize that evaluating the self-sustaining status of a population will almost always necessitate independent biological information, and such biological information alone only becomes controversial when stocking is present. We outline below a set of guidelines for evaluating huchen populations includes information where available for our study populations and how we used this information to support our conclusions. We additionally provide cautionary advice for the weaknesses of such evaluations dependent on the available information, the intensity of stocking, and the general management regime.

Presence of multiple year classes, including juveniles

A self-sustaining population, under normal circumstances, should reveal multiple year classes, including juvenile or even young-of-the-year individuals. However, year-class failure in stream fishes is common and can be caused by natural environmental conditions (e.g., Letcher \& Terrick, 2001; Borgstrom \& Museth, 2005; Lobón-Cerviá, 1996). For huchen, anthropogenically altered hydrology and substrate conditions are a common problem in central Europe that can also lead to reproductive failure (Sternecker et al., 2014), and thus these factors as well as natural floods in regulated rivers could easily lead to frequent reproductive failure. However, with a long-lived, top-end predator, such year-class drop-out needs not imply a lack of sustainability. In our study, from 95 individuals sampled from the Mur River in and around Graz (including both north and south of the city), 46 $(48 \%)$ were categorized as adults (i.e., $>60 \mathrm{~cm}$ ), 41 $(43 \%)$ as juveniles (i.e., $<60 \mathrm{~cm}$ ), and eight $(8 \%)$ of unknown size. Among the juveniles, six ca. $1+$ fish (i.e., $<200 \mathrm{~mm}$ ) were caught within the city limits in the main channel of the Mur in 2008, and in 200917 individuals estimated to be $2+$ years old (ca. 230-280 mm) were captured, primarily in an artificial 
side channel of the Mur (within the city limits, with its inlet just at the northern border of city). This side channel is periodically drained in order to maintenance small hydroelectric turbines and to protect these turbines during flood events. These results supported the anecdotal view of the fishery organization that 2008 was a successful reproduction year for huchen in and around the city. Additionally, as all known stocked fish in this region, since 1998, were 3+ years old (ca. $42 \mathrm{~cm}$, Table 5), we are confident that these individuals represent natural reproduction in Graz and the Graz vicinity. When stocking takes place, but no $1+$ or $2+$ fish are used, the confirmation of reproductive success rests solely on documenting the presence of such year classes. Young-of-the-year huchen are less easily documented, and especially in the early stages, never seen by anglers and rarely if ever caught in traditional sampling campaigns. Documenting the occurrence of larval huchen requires well-timed and precisely located (just below spawning sites) larval sampling nets. Such a sampling strategy has been carried out over a number of years in the upper Mur River, and larval huchen were caught in each of the years sampled (2005-2009; summarized in Schmutz et al., 2011).

\section{Documentation of spawning}

There was no systematic survey of spawning redds or spawning individuals undertaken during this study. Nonetheless, opportunistic observations and photography document multiple spawning sites in Graz and its vicinity during the study period. On April 2, 2011, spawning huchen were opportunistically observed and photographed in the middle of Graz by the first author and a television camera team (Fig. 4a). In the subsequent weeks, 14 spawning redds were documented, both in and around the city, including in the construction site of a soon-to-be-filled reservoir $2 \mathrm{~km}$ south of the city (Weiss \& Schenekar, 2012; Fig. 4b), and ca. $10 \mathrm{~km}$ north of the city in a stretch of yet another planned hydropower project (Fig. 4c). Documentation of spawning is an independent supportive indicator of a natural sustainable population, but without documentation of young fish, one cannot be sure that such spawning events lead to successful recruitment, especially if high water events follow the spawning period.
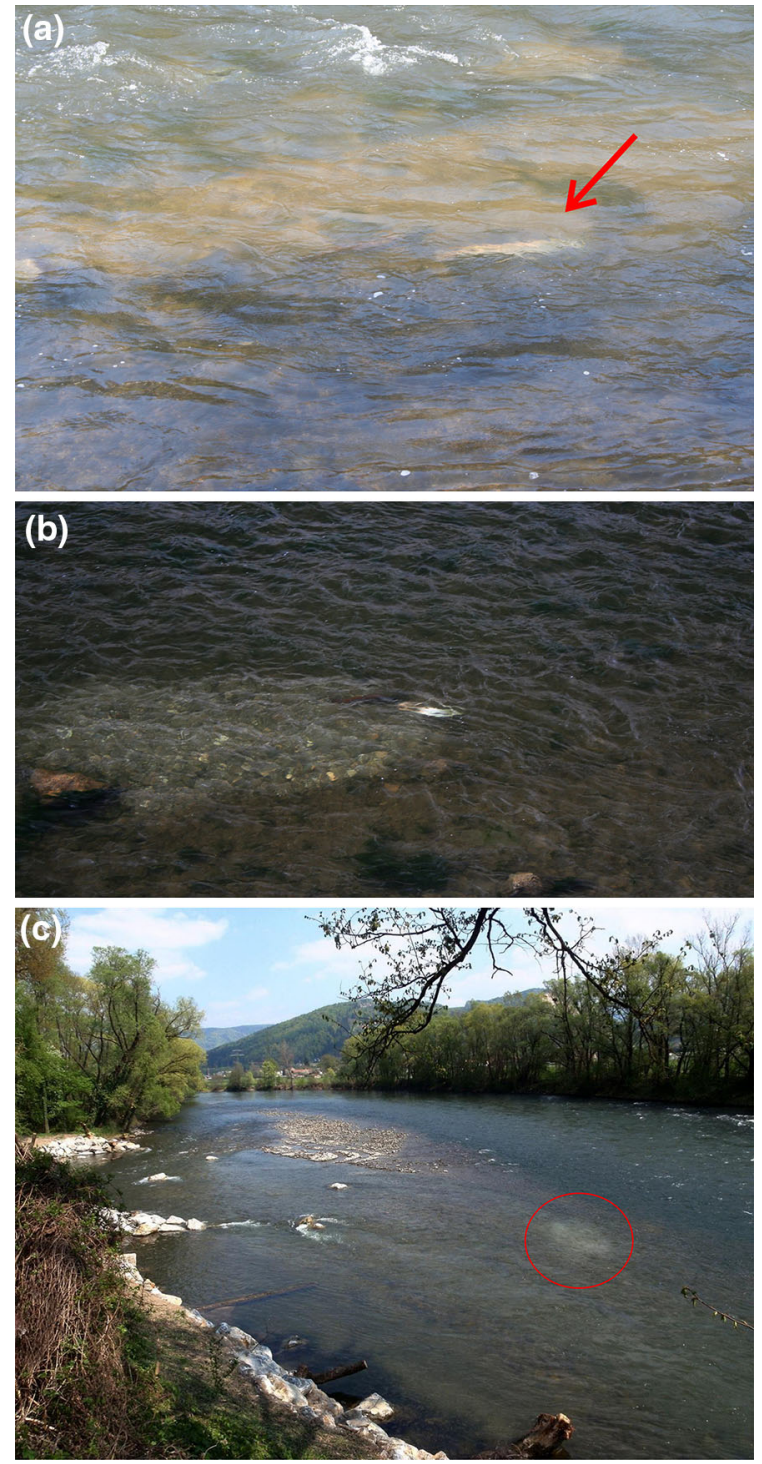

Fig. 4 a A pair of spawning huchen documented in the Mur River, in middle of Graz (next to a large public park, April 3, 2011); b Spawning huchen at the Gössendorf dam construction site ca. $2 \mathrm{~km}$ south of Graz on April 17, 2011; c A huchen spawning redd spotted in the Mur River near Stübing approximately $10 \mathrm{~km}$ north of Graz on April 8, 2011

\section{Other tagging programs}

While not done in our study, it would also be possible to batch-tag stocked fish (e.g., with coded wire tags, visible implant tags, or fluorescent marking) to support differentiation from wild fish, although it would only be sensible if all stocked fish are marked, with the choice of tag, cost, and efficiency variable dependent 
on the size of the fish being stocked as well as the expected recovery methodology (Drenner et al., 2012). While not entirely new, recent developments in otolith marking show increased promise for such questions, as the natural differences in water chemistry between rivers and hatcheries should provide a natural mark in otoliths that allow distinction between hatchery and wild fish-albeit individuals must be sacrificed to retrieve the information (Barnett-Johnson et al., 2008). Otolith marking with fluorescent alizarin red S even at the embryo stage (Unfer \& Pinter, 2013; Martyniak et al., 2013) also provides relatively inexpensive mass marking, again with the need to sacrifice the fish to retrieve the information.

In summary, the best conditions for demonstrating that a specific population of huchen is self-sustaining are when there is no stocking. We highly encourage that natural huchen populations be managed without stocking whenever possible (Ihut et al., 2014). If stock enhancement is carried out, managers should ensure that genetic samples be taken and properly stored from ALL brood parents, which will enable genetic-based parentage analysis of the wild population at a future date. Simply marking or demonstrating that some stocked fish survive is wholly insufficient for evaluating the self-sustainability of any population, as it is difficult to demonstrate if this survival is compensatory within the population (i.e., the population density will remain the same over time whether fish are stocked or not).

Acknowledgments We thank the provincial government of Styria for the financing of the project, Robert Steinbrugger for developing the microsatellite assay in the framework of his Master's degree, members of the "Arbeiterfischereiverein Graz" and the Institute of Hydrobiology and Aquatic Ecosystem Management for providing many samples. We also thank Franz Keppel for the use of the photographs in Fig. 4.

Open Access This article is distributed under the terms of the Creative Commons Attribution 4.0 International License (http:// creativecommons.org/licenses/by/4.0/), which permits unrestricted use, distribution, and reproduction in any medium, provided you give appropriate credit to the original author(s) and the source, provide a link to the Creative Commons license, and indicate if changes were made.

\section{References}

Barnett-Johnson, R., T. E. Pearson, C. Ramos, C. B. Grimes \& R. B. MacFarlane, 2008. Tracking natal origins of salmon using istotopes, otoliths, and landscape geology. Limnology and Oceanography 53(4): 1633-1642.

Belkhir, K., P. Borsa, L. Chikhi, N. Raufaste \& F. Bonhomme, 1996-2004. GENETIX 4.05, logiciel sous Windows TM pour la genetique des populations. Université de Montpellier II, Montpellier.

Borgstrøm, R. \& J. Museth, 2005. Accumulated snow and summer temperature: critical factors for recruitment to high mountain populations of brown trout (Salmo trutta L.). Ecology of Freshwater Fish 14: 375-384.

Diggs, M. D. \& W. R. Ardren, 2008. Characterization of 12 highly variable tetranucleotide microsatellite loci for Arctic grayling (Thymallus arcticus) and cross amplification in other Thymallus species. Molecular Ecology Resources 8: 828-830.

Diniz, F. M., A. Iyengar \& P. S. D. C. Lima, 2007. Application of a double-enrichment procedure for microsatellite isolation and the use of tailed primers for high throughput genotyping. Genetics and Molecular Biology 30: 380-384.

Drenner, S. M., T. D.., Clark, C. K, Whitney, E.G., Martins, S.J., Cooke, \& S.G, Hinch, 2012. A synthesis of tagging studies examining the behaviour and survival of anadromous salmonids in marine environments. PLOS ONE 7(3)-e31311.

Excoffier, L., G. Laval \& S. Schneider, 2005. Arlequin (version 3.0): an integrated software package for population genetics data analysis. Evolutionary Bioinformatics online 1: 47-50.

EU Habitats Directive (1992) Available at http://ec.europa.eu/ environment/nature/legislation/habitatsdirective/index_en. htm)

Freyhof J., \& M. Kottelat, 2008. Hucho hucho In: IUCN 2013. IUCN Red List of Threatened Species. Version 2013.1. $<$ www.iucnredlist.org $>$. Downloaded on September, 12th 2013.

Freyhof, J., S., Weiss, A., Adrović, M., Ćaleta, A., Duplić, B., Hrašovec, B., Kalamujić, Z., Marčić, D., Milošević, M., Mrakovčić, D., Mrdak, M., Piria, P., Simonović, S., Šljuka, T.,Tomljanović \& D. Zabric, 2015. The Huchen Hucho hucho in the Balkan region: Distribution and future impacts by hydropower development. Technical report produced for RiverWatch \& EuroNatur, 30 pp. (available at http:// balkanrivers.net/sites/default/files/Huchen_Study_2015. pdf).

Froufe, E., I. Knizhin \& S. Weiss, 2005. Phylogenetic analysis of the genus Thymallus (grayling) based on mtDNA control region and ATPase 6 genes, with inferences on control region constraints and broad-scale Eurasian phylogeography. Molecular Phylogenetics and Evolution 34: 106-117.

Geist, J., M. Kolahsa, B. Gum \& R. Kuehn, 2009. The importance of genetic cluster recognition for the conservation of migratory fish species: the example of the endangered European huchen Hucho hucho (L.). Journal of Fish Biology 75: 1063-1078.

Goudet, J., 2002. FSTAT (Version 2.9.3.2): a computer program to estimate and test gene diversities and fixation indices. Available at: http://www.unil.ch/izea/softwares/fsat.html.

Holčík, J., 1990. Conservation of the huchen, Hucho hucho (L.), (Salmonidae) with special reference to Slovakian rivers. Journal of Fish Biology 37: 113-121.

Ihut, A., A. Zitek, S. Weiss, C. Ratschan, G. Holzer, T. Kaufmann, D. Cocan, R. Constantinescu \& V. Miresan, 2014. 
Danube salmon (Hucho hucho) in Central and South Eastern Europe: a review for the development of an international program for the rehabilitation and conservation of Danube salmon populations. Bulletin UASVM Animal Science and Biotechnology 71: 86-101.

IUCN 2012. Guidelines for application of IUCN Red List Criteria at Regional and National Levels: Vesion 4.0. Gland, Switzerland and Cambridge, UK. ISBN: 978-2-8317-12475.

Jones, A. G., C. M. Small, K. A. Paczolt \& N. L. Ratterman, 2010. A practical guide to methods of parentage analysis. Molecular Ecology Resources 10: 6-30.

Kalinowski, S. T., M. L. Taper \& T. C. Marshall, 2007. Revising how the computer program CERVUS accommodates genotyping error increases success in paternity assignment. Molecular Ecology 16: 1099-1106.

Kandpal, R. P., G. Kandpal \& S. M. Weissman, 1994. Construction of libraries enriched for sequence repeats and jumping clones, and hybridization selection for regionspecific markers. Proceedings of the National Academy of Sciences, USA 91: 88-92.

Karagyozov, L., I. D. Kalcheva \& V. M. Chapman, 1993. Construction of random small-insert genomic libraries highly enriched for simple sequence repeats. Nucleic Acids Research 21: 3911-3912.

Kijas, J., J. Fowler, C. Garbett \& M. Thomas, 1994. Enrichment of microsatellites from the citrus genome using biotinylated oligonucleotide sequences bound to streptavidincoated magnetic particles. Biotechniques 16: 656-660.

Letcher, B. H. \& T. D. Terrick, 2001. Effects of developmental stage at stocking on growth and survival of Atlantic salmon fry. North American Journal of Fisheries Management 21(1): 102-110.

LobonCervia, J., 1996. Response of a stream fish assemblage to a severe spate in northern Spain. Transactions of the American Fisheries Society 125: 913-919.

Marić, S., S. Alekseyev, A. Snoj, O. Askeyev, I. Askeyev \& S. Weiss, 2014. First mtDNA sequencing of Volga and Ob basin taimen Hucho taimen: european populations stem from a late Pleistocene expansion of $\mathrm{H}$. taimen out of western Siberia and are not intermediate to Hucho hucho. Journal of Fish Biology 85: 530-539.

Maric, S., A. Razpet, V. Nikolic, A. Snoj \& P. Simonovic, 2014. Analaysis of genetic structure of huchen (Hucho hucho) in Serbia inferred from mitochondrial and nuclear DNA. Acta Veterinaria-Beograd 64: 236-244.

Martyniak, A., K., Stanczak, J., Kozlowski, K., Mierzejewska, B., Wzatiek, A.M., Lejk, \& P., Hliwa,2013. Alizarin mark retention in the otoliths of whitefish (Coregonus lavaretus $\mathrm{f}$. laveretus L.) from Lake Lebsko, Poland. 64, 83-89 Biology and Management of Coregonid Fishes: 2011, Book Series, Advances in Limnology.

McPherson, A. A., P. T. O'Reilly, T. L. McParland, M. W. Jones \& P. Bentzen, 2001. Isolation of nine novel tetranucleotide microsatellites in Atlantic herring (Clupea harengus). Molecular Ecology Notes 1: 31-32.

Paetkau, D., 1999. Microsatellites obtained using strand extension: an enrichment protocol. Biotechniques 26(690-692): 694-697.

Schmutz, S., A. Zitek, S. Zobl, M. Jungwirth, N. Knopf, E. Kraus, T. Bauer \& T. Kaufmann, 2002. Integrated approach to the conservation and restoration of Danube salmonid, Hucho hucho, popualtions in Austria. In Collares-Pereira, M. J., M. M. Coelho \& I. G. Cowx (eds), Freshwater Fish Conservation: Options for the Future. Fishing News Books. Blackwell Science, Oxford: 157-173.

Schmutz, S., C., Wiesner, S., Preis, S., Muhar, G., Unfer, \& M. Jungwirth, 2011. Beurteilung der ökologischen Auswirkungen eines weiteren Wasserkraftausbaus auf die Fischfauna der Mur. Studie i. A. des Amts. Der Steiermärkischen Landesregierung, FA 19A, 64 pp.

Schuelke, M., 2000. An economic method for the fluorescent labeling of PCR fragments. Nature Biotechnology 18: 233-234.

Scribner, K. T., J. R. Gust \& R. L. Fields, 1996. Isolation and characterization of novel salmon microsatellite loci: crossspecies amplification and population genetic applications. Canadian Journal of Fisheries and Aquatic Sciences 53: 833-841.

Sternecker, K., M. Denic \& J. Geist, 2014. Timing matters: species-specific interactions between spawning time, substrate quality, and recruitment success in three salmonid species. Ecology and Evolution 4: 2749-2758.

Tong, G., Y. Kuang, J. Yin, L. Liang \& X. Sun, 2006. Isolation of microsatellite DNA and analysis on genetic diversity of endangered fish, Hucho taimen (Pallas). Molecular Ecology Notes 6: 1099-1101.

Unfer, G. \& K. Pinter, 2013. Marking otoliths of brown trout (Salmo trutta L.) embryos with alizarin red S. Journal of Applied Ichthyology 29(2): 470-473.

Van Oosterhout, C., W. F. Hutchinson, D. P. M. Wills \& P. Shipley, 2004. Micro-checker: software for identifying and correcting genotyping errors in microsatellite data. Molecular Ecology Notes 4: 535-538.

Weir, B. S., 2007. The rarity of DNA profiles. Annals of Applied Statistics 1: 358-370.

Weiss, S., S. Marić \& A. Snoj, 2011. Regional structure despite limited mtDNA sequence diversity found in the endangered Huchen, Hucho hucho (Linnaeus, 1758). Hydrobiologia 658: 103-110.

Weiss, S. \& T. Schenekar, 2012. Mur-Huchen: erweiterung des genetischen Nachweises von Fremdbesatz und natürliche Reproduktion. Österreichs Fischerei 65: 136-147.

Winkler, K. A. \& S. Weiss, 2008. Eighteen new tetranucleotides microsatellite DNA markers for Coregonus lavaretus cloned from an alpine lake population. Molecular Ecology Resources 8: 1055-1058. 